\section{More on DNA typing dispute}

SIR - Lander and Budowle ${ }^{1}$ imply that the inferential problems of forensic genetics have been solved and that further studies are not warranted. Perhaps a spectator, with an interest in the more difficult, but equally confused, problems of linkage analysis could comment. The arguments of the authors and their associates instructed and entertained readers of Science two years ago in a series of articles when the differences in the misunderstandings of the various contestants were to some extent clarified. They have recently been catalogued and dissected in detail by Morton ${ }^{2}$. Different misunderstandings are hardly an adequate justification for gratuitous advice.

Forensic genetics covers a wide field, sometimes involving degraded specimens, or inferences on genetic mixtures on good samples (paternity tests), or the resolution of mixtures in degraded mixtures (rape). If there is an adequate supply of fresh blood, the various shot-gun methods pioneered by Jeffreys provide an unambiguous answer, but, as with ordinary fingerprints, convey too much information for mathematical analysis and are simple enough for judges and jurors to comprehend and interpret without advice. The quantity and quality of the blood available in the O. J. Simpson case was not stated.

If samples are limited or degraded, techniques involving amplification of short segments of DNA are necessary, and their analysis involves the summation of the evidence from each part. While it is obvious if any result differs, difficulties arise when they do not. This is the central problem of classification, and indeed of language, and can hardly be dismissed as a non-problem in a few pages.

Even the simplest model presents formidable difficulties. Suppose we have a bag of coins, one of which is doubleheaded. A coin is removed and tossed, and a decision with consequences of life or death has to be made on the result of a defined number of tosses of a single coin selected at random. If any tail appears, the problem is solved. If not, the odds against the coin selected being a regular coin after ten tosses are about a thousand to one. However, if there are a thousand coins in the bag, the odds against this coin having been selected are also a thousand to 1 . It is not possible to give judgement without knowing the size of the bag, as Laplace observed in a similar context. In this case the regular coins are unbiased. In the forensic case of murder they are not. Murders preferentially involve relatives and neighbours.

Lander and Budowle's argument appears to be that if the bag were big enough to carry, and the coins of a regular variety, then we could assume a maximum size, or ceiling, and just keep tossing for as long as necessary. This is obviously true, but the 'ceiling' is so arbitrary that it can hardly 'support' any very elaborate inference. Even this has problems, for the 'regular' coins are not unbiased, as the population of the world does not consist of unrelated individuals: we are all relatives and most of us have several close relatives.

This introduces even graver problems if segments of chromosomes, as well as murderers, are assumed selected at random. A solution that could imply, at odds ratios comparable to the population of the world, that no two persons would have any realistic chance of being identical seems seriously flawed.

The courts will have enough problems in the O. J. Simpson case. It would be unfortunate if public appreciation of population genetics, a subject largely developed in the first half of this century, were to become one of comic denigration and add support for creationism and genetical brands of political correctness.

\section{J.H. Edwards}

University of Cambridge,

Genetics Laboratory,

Department of Biochemistry,

South Parks Road,

Oxford OX13QU, UK

SIR - Although the National Institute of Justice (NIJ) does not, as a general rule, take positions on issues of this sort, we wish to clarify one misunderstanding in the article by Lander and Budowle ${ }^{1}$. They write that: "The NRC [National Research Council] - at the urging of the National Institute of Justice, representing the academic wing of forensic scientists - has concluded that the best solution is to constitute another ad hoc committee on DNA fingerprinting, composed primarily of statisticians and population geneticists".

First, it is not the National Institute of Justice that urged the NRC to convene this board; the NRC jealously guards its independence. Several people suggested that a new committee be convened, including the director of the Federal Bureau of Investigation (FBI), William Sessions, in a letter to the NRC. NIJ was not one of those, but when the NRC decided to convene this committee, it approached NIJ for funding. At the urging of the FBI, and others, NIJ agreed to provide much of the funding for the new committee.

Second, the NIJ does not represent "the academic wing of forensic scientists". It doesn't represent any group of forensic scientists, academic or otherwise. It supports well-designed research into the forensic sciences by practitioners in crime laboratories, academics in universities and others, including work in the labor- atories of federal law-enforcement agencies. Every peer-review panel at NIJ includes practitioners who ensure that NIJ research meets the real needs of US crime laboratories at the local, state and federal levels, as well as uniquely qualified experts from academic life and the federal and military forensic laboratories.

The role of the National Institute of Justice is unique. It serves as an independent research agency supporting all levels of the law enforcement and criminal justice system, from the local to the federal. It has, for nearly a quarter of a century, been the principal source of federal funds for the forensic sciences community and takes very seriously the legislative directive that it serve the practical needs of the law enforcement and criminal justice communities.

\section{David G. Boyd}

(Director, Science and Technology)

National Institute of Justice,

Washington, DC 20531, USA

SIR - Having been involved in several trials using DNA typing, I wish to reply to Lewontin and $\mathrm{Hartl}^{3,4}$. Lewontin states “. . . juries are no more capable of understanding probability statements than they are of interpreting any other piece of highly technical information. ..,

Juries have been coping with probability statements with respect to serological typing with judiciousness and effectiveness for decades. DNA testing is not qualitatively different from serology. Perhaps Lewontin is reacting to the phenomenon that, with rare exceptions, judges and juries who have listened to his railing against DNA testing have chosen to be persuaded by the opposition's point of view. This does not prove that juries are incapable of understanding the issues, but merely attests to the lack of persuasiveness of Lewontin's arguments ${ }^{3}$.

It is impossible to determine with certainty the genetic group or subgroup of any accused individual. Even in the rare instances when extensive pedigree information is available, experience with paternity testing has demonstrated that a significant fraction of paternity is misassigned. The use of the ceiling principle ensures that the suspect will be afforded the maximum conservatism with respect to the probability estimates and should not be considered an 'interim' solution.

I agree with Lewontin that the refusal by the FBI laboratory of outside inspection and data verification is troubling, especially when I have been called upon to testify in support of its findings. Regardless of the reasons for this policy, I believe that the FBI laboratory should be held to the same standards and requirements as other laboratories.

The term DNA fingerprinting, as I understand it, refers to a patented process of Cellmark Diagnostics involving multi- 